\title{
Thalidomide as an effective treatment in a case of Osler Weber Rendu syndrome: a case report
}

\author{
Titli Bandyopadhyay ${ }^{1}, \mathrm{~V}$ T Anand ${ }^{2}$, Dibyendu Gangopadhyay ${ }^{3}$ \\ ${ }^{1}$ Senior Resident, Department of ENT, IQ City Medical College, Durgapur, West Bengal, \\ ${ }^{2}$ Consultant, Department of ENT, Manipal Hospital, Bangalore, Karnataka, \\ ${ }^{3}$ Tutor, Department of Microbiology, Gouri Devi Institute of Medical Sciences and Hospital, Durgapur, West Bengal
}

Osler Weber Rendu Syndrome (OWRS), or Hereditary Hemorrhagic telangiectasia (HHT) is an autosomal dominant disease presents with epistaxis, telangiactesia and multiorgan vascular dysplasia. Recurrent epistaxis is common in these patients and various local forms of therapy is tried to treat the condition, but there is lack of definitive and effective treatment. We present a patient of HHT with severe recurrent epistaxis successfully treated with thalidomide.

Key words: Epistaxis, Hereditary hemorrhagic telangiectasia, Thalidomide

\section{INTRODUCTION}

Hereditary Hemorrhagic Telangiectasia (HHT), or Osler Weber Rendu syndrome is an autosomal dominant disorder where telangiectic capillaries result in bleeding episodes, notably from nose and gastro-intestinal tract. Arteriovenous malformations are seen in various viscera including lung, kidney, liver or brain. Several episodes of moderate to severe epistaxis is a common and troublesome symptom, starts around age of twelve and occurs in $>95 \%$ of affected individuals by middle age. ${ }^{1}$ This condition is caused by mutations in the genes encoding ENG (endoglin) and activin receptor like kinase, which are endothelial cell receptors for transforming growth factor-beta (TGF- $\beta$ ), a potent angiogenic cytokine. $^{2}$ The disease is common in all ethnic and racial groups and prevalence ranges from 1 in 5000 to 10000 persons. ${ }^{3}$ Various operative and non operative therapies including electrocauterisation and tranexamic acid have been tried to treat the epistaxis in HHT. In this report we present a patient with HHT treated with thalidomide only for recurrent epistaxis.

\section{CASE REPORT}

A 42 year Bengali male patient presented to Ear Nose Throat out -patient department (ENT OPD) at Manipal Hospital Bangalore on 1 January, 2013 with complaints of recurrent episodes of nose bleed for about 10 years. Bleeding used to occur spontaneously, from both nostrils, right side more frequently than left side. The patient had hospital admission in several occasions for nose bleed and treated with nasal packing, cauterization of bleeding points, iron supplements and parenteral tranexamic acid. He does not have history of bleeding from any other site. His father had similar nose bleeding episodes and of late, his son also has developed nose bleeds, in a milder form and frequency.

On examination in ENT OPD, the patient had pallor, there was no active bleeding, telangiectic vessels seen over bilateral Little's area. On Diagnostic nasal endoscopy, telangiectasia over full length of septum and turbinates noted along with deviated nasal septum towards right. Upon examination of the oral cavity (Figures 1 and 2), telangiectic vessels seen over lips, tongue and buccal 


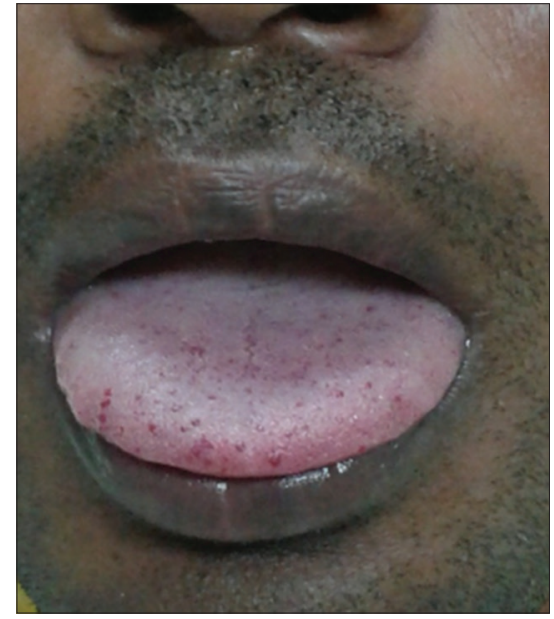

Figure 1: Telangiectasia over tongue

mucosa. Hemogram of the patient revealed Hemoglobin of $9 \mathrm{gm} / \mathrm{dl}$. As per Shovlin et al diagnostic criteria (2000), ${ }^{4}$ the patient was diagnosed as Osler Weber Rendu syndrome. The patient was started on thalidomide $50 \mathrm{mg}$ per day at bed time for a month and dose increased to $100 \mathrm{mg}$ at bed time for three months. The patient was reviewed up to 2 years at 3 months interval. His epistaxis was controlled, no major nose bleed occurred apparently. Hemoglobin improved to $12 \mathrm{gm} / \mathrm{dl}$ (follow up at 3 month) without any significant side effects reported by the patient except for mild sedation. His blood investigations including Hemogram, liver and renal function tests were normal at follow up.

\section{DISCUSSION}

Diagnosis of Osler Weber Rendu disease can be made definitely if three of the following criteria are present and suspected if two criteria are present. (1) spontaneous and repeated epistaxis(epistaxis at night to be highly considered), (2) multiple skin or mucous membranes of telangiectasia: include the lips, mouth, fingers and nose, etc; (3) visceral arteriovenous malformations: can be expressed in the lung, brain, liver, kidney, gastrointestinal tract and other parts; (4) family history. ${ }^{4}$ The manifestations of OWRS result from vascular abnormalities, the telangiectasias, which are nothing but small A-V shunts involving dilated arterioles and vennules. ${ }^{5}$ Management options available for epistaxis include nasal packing, cauterization, embolisation, arterial ligation or nasal closure in extreme cases, which provide variable symptom free period but are ineffective in long term. ${ }^{6}$ Role of medical therapy is limited, use of tranexamic acid or aminocaproic acid, correction of anemia with iron supplement and blood transfusion, has no definitive role and not without side effects. Since this patient has received various treatments before and since there was no active bleeding, no surgical intervention was planned. According

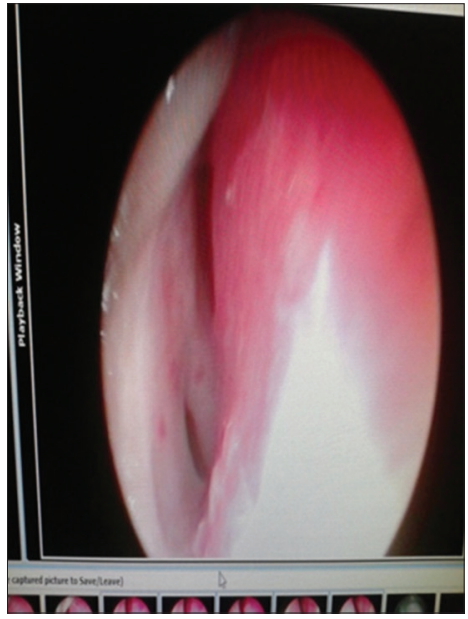

Figure 2: Nasal endoscopic view of telangiectasia

to published articles on OWRS, very low dose Bevacizumab would have been a choice ${ }^{7}$, but considering the toxicity profile and cost, this drug was not advised.

In the pathogenesis of OWRS, angiogenesis had been proposed. Therefore, anti angiogenic factors can be useful in treating vascular malformations in this condition. Thalidomide inhibits tumor necrosis factor alpha (TNF $\alpha$ ) thereby acting as a potent anti angiogenic drug. It has lesser side effects (peripheral neuropathy, sedation, thromboembolism), ${ }^{8}$ easily available, and cheap. Earlier case studies also suggest use of oral thalidomide stimulates vessel maturation and helps in reducing epistaxis in patients of HHT/OWRS.' After thalidomide treatment, the severity of nasal bleed significantly reduced in our patient, his hemoglobin level improved and there was no side effects reported by the patient. This report suggests that thalidomide could be an effective treatment of spontaneous epistaxis in patients with OWRS if used with caution with monitoring its ill effects and after proper case selection.

\section{REFERENCES}

1. Harrison's Principles of Internal Medicine. $18^{\text {th }}$ edition, chapter 115; page 973

2. Davidson's principle and practice of medicine. $21^{\text {st }}$ edition, chapter 24;page 1045

3. Kjeldsen $A D$, Vase $P$ and Green A. Hereditary hemorrhagic telangiectasia: a population-based study of prevalence and mortality in Danish patients. J Intern Med 1999; 245: 31-39.

4. Shovlin $\mathrm{CL}$, Guttmacher AE, Buscarini $\mathrm{E}$, Faughnan ME, Hyland RH, Westermann CJ, et al. Diagnostic criteria for hereditary hemorrhagic telangiectasia (Rendu-Osler-Weber Syndrome). Am J Med Genet 2000; Mar 6:91 (1): 66-67.

5. Sharatkumar AA and Shapiro A. Hereditary hemorrhagic telangiectasia. Hemophilia 2008; 14:1269-1280.

6. Pau H, Carney AS and Murty GE. Hereditary hemorrhagic telangiectasia (Osler-Weber-Rendu syndrome): 
otorhinolarngological manifestations. Clin Otolaryngol Allied Sci 2001; 26: 93-98.

7. Thompson AB, Ross DA, Berard P, Bodine JF, Livada $N$ and Richer SL. Very low dose bevacizumab for the treatment of epistaxis in patients with hereditary hemorrhagic telangiectasia. Allergy Rhinol (Providence) 2014; 5(2): e91-e95.
8. Ghobrial IM and Rajkumar SV. Management of Thalidomide Toxicity. J Support Oncol 2003; 1(3): 194-205.

9. Lebrin F, Srun S, Raymond K, Martin S, Brink SV, Freitas C, et al. Thalidomide stimulates vessel maturation and reduces epistaxis in individuals with hereditary hemorrhagic telangiectasia. Nat Med 2010; 16(4):420-428.

Authors Contribution:

TB - Data Acquisition, Manuscript preparation; VTA - Concept of case presentation and final approval; DG - Design and Manuscript editing.

Source of Support: Nil. Conflict of Interest: None. 